\title{
Decline in annual lung function in workers exposed to asbestos with and without pre-existing fibrotic changes on chest radiography
}

\author{
Toshio Nakadate
}

\begin{abstract}
Objectives-To examine whether or not workers with pre-existing mild pulmonary fibrosis have accelerated decline in forced expiratory volume in one second $\left(F E V_{1}\right)$ or forced vital capacity (FVC), under low level exposure to chrysotile asbestos.

Methods-All male workers in two asbestos manufacturing factories were followed up annually for six years to compare their declines in FEV 1 and FVC. The values of $F E V_{1}$ and FVC were divided by the square of the person's height to adjust for body size differences $\left(F E V_{1} / \mathbf{H t}^{2}\right.$ and FVC/ $/ \mathrm{Ht}^{2}$, respectively). Annual change was calculated for each subject as a slope of the simple linear regression with $\mathrm{FEV} / \mathrm{Ht}^{2}$ or $\mathrm{FVC} / \mathrm{Ht}^{2}$ regressed according to age. Analysis was conducted on 242 middle aged workers who had normal routine spirometry values, normal chest radiographs or mild pneumoconiosis up to $1 / 2$ grade, without changes either in smoking habit or severity of pneumoconiosis during the study period, and with acceptable spirograms in three or more surveys. The occupational environment, in terms of chrysotile asbestos, had been well controlled below the threshold limit value of Japan at that time-namely, 2 fibres $/ \mathrm{ml}$.
\end{abstract}

Results-There was no significant effect from the interaction between pre-existing mild pulmonary fibrosis and a low level of exposure to chrysotile asbestos on the accelerated annual decline of $F E V_{1} / H^{2}$ or FVC/Ht ${ }^{2}$. Fibrosis significantly contributed to annual changes in $F E V_{1} / \mathbf{H t}^{2}$, even after adjustment for mean $F E V_{1}$ and smoking. The point estimate of the contribution was $-4.9 \mathrm{ml} / \mathrm{m}^{2} / \mathrm{y}$. No significant independent contribution of exposure was found in decline of either FEV ${ }_{1} / \mathrm{Ht}^{2}$ or $\mathrm{FVC} / \mathrm{Ht}^{2}$.

Conclusions-Pre-existing pulmonary fibrosis is an independent risk factor for accelerated annual decline of $\mathrm{FEV}_{1}$, even when mild and stable. Additional decline due to exposure to chrysotile asbestos is less probable if it is well controlled under the current threshold limit value.

(Occup Environ Med 1995;52:368-373)

Keywords: pneumoconiosis; asbestos; spirometry
Recent advances in industrial hygiene techniques have remarkably improved the occupational environment, and currently actual exposure to asbestos and other mineral dusts and fibres is generally controlled at a low level. The number of new cases with severe fibrotic changes in the lungs has been decreasing in Japan and most other developed countries.

In contrast, considerable concern has come to be directed towards work related chronic obstructive pulmonary disease (COPD),${ }^{1}$ one of the important outcomes of inhaling harmful substances under such low exposure conditions. Accelerated annual loss of forced expiratory volume in one second $\left(\mathrm{FEV}_{1}\right)$ has been reported in several longitudinal studies on coal miners, ${ }^{23}$ gold miners, ${ }^{4}$ and asbestos cement workers. ${ }^{5}$ Little is known about the effect of pre-existing pulmonary fibrosis on the subsequent annual decline of $\mathrm{FEV}_{1}$ under the current low exposures to mineral dusts and fibres.

The purpose of this analysis was to examine the synergistic effect of low exposure to chrysotile asbestos and pre-existing mild pulmonary fibrosis, on the mean annual decline in $\mathrm{FEV}_{1}$ and forced vital capacity (FVC), together with their independent effects on these two indices.

\section{Subjects and methods}

SUBJECTS

Study subjects were recruited from two asbestos manufacturing factories where calcium silicate boards and joint materials including asbestos were produced. All male employees of the factory were first examined in 1985 by spirometry, chest radiography, and questionnaire. They were followed up annually up to 1991 (excluding 1987) with the same protocol as used in the first assessment. Of this cohort, we limited our scope of analysis to those who had worked in these factories for three years or more between 1985 and 1991 to obtain a reliable estimate of annual change in spirometric indices. Thus the original sample was 351 subjects. The age range of the cohort at the beginning of this study was from 19 to 58 .

\section{SPIROMETRY}

The procedure used has been described in detail elsewhere. ${ }^{6}$ Briefly, spirograms were measured with a dry rolling seal spirometer (Chestac 65, Chest Co, Japan). Subjects, in a standing position, were asked to repeat the forced expiration manoeuvre at most seven 
times to obtain acceptable, reproducible results. Nose clips were not used because an open circuit method was adopted. Usual body temperature, pressure, and saturation correction and back extrapolation correction were carried out. Whether or not each manoeuvre was acceptable was evaluated by the following criteria: starting without hesitation, apparent maximal effort, and smooth continuous exhalation without cough. Reproducibility was judged by the criteria of the American Thoracic Society, ${ }^{7}$ based on the measured values, and on the shapes of flow-volume and flow-time curves. In each survey, the subjects with at least two reproducible spirograms were considered acceptable. The figures of $\mathrm{FEV}_{1}$ and FVC used in this analysis were derived from the best manoeuvre with the largest sum of FVC and $\mathrm{FEV}_{1}$. To minimise the measurement bias across the surveys, all examinations were carried out by one examiner with the same spirometer throughout all the surveys.

CROSS SECTIONAL AND LONGITUDINAL INDICES At first, we examined several models for $\mathrm{FEV}_{1}$ and FVC to different powers of height, to standardise the value according to body size. The results showed that the height squared $\left(\mathrm{Ht}^{2}\right)$ model seemed to be appropriate in terms of this standardisation. We then used the $\mathrm{Ht}^{2}$ proportional values of $\mathrm{FEV}_{1}$ and $\mathrm{FVC}$ $\left(\mathrm{FEV}_{1} / \mathrm{Ht}^{2}\right.$ and $\mathrm{FVC} / \mathrm{Ht}^{2}$, respectively) in this analysis, to adjust for height differences. Annual changes in $\mathrm{FEV}_{1} / \mathrm{Ht}^{2}$ and $\mathrm{FVC} / \mathrm{Ht}^{2}$, a longitudinal index denoted by "slope" in this paper, were calculated for each subject as the slopes of simple linear regressions in which $\mathrm{FEV} / \mathrm{Ht}^{2}$ and $\mathrm{FVC} / \mathrm{Ht}^{2}$ were regressed by age. A cross sectional index, $\mathrm{FEV}_{1} / \mathrm{Ht}^{2}$ level-the mean $\mathrm{FEV}_{\mathbf{1}} / \mathrm{Ht}^{2}$ value of each subject during the follow up period-was used. The first $\mathrm{FEV}_{1} / \mathrm{Ht}^{2}$ value for each worker was also considered, but it seemed inappropriate because of the relatively large error in $\mathrm{FEV}_{1}$ each time it was measured in comparison with the size of the decline in $\mathrm{FEV}_{1}$. By using mean values, the error of each measurement could be averaged.

\section{OCCUPATIONAL EXPOSURE}

Among primary sources of exposure to asbestos during the follow up were exposure to the processing of chrysotile asbestos in the production of calcium silicate boards, some joint and sealing materials, and insulating products. Periodic monitoring of the occupational environment has been carried out not only in all work areas where asbestos was used, but other possible areas such as storage and stock yards. Based on records made during the study period, the time weighted average (TWA) concentration of chrysotile asbestos fibres has been controlled to below 0.5 fibres $/ \mathrm{ml}$, well below the permissible levels of occupational exposure in Japan-namely, two fibres $/ \mathrm{ml}$ for chrysotile. ${ }^{8}$ The company records suggested that higher exposure might have been probable in the past, at least before the mid-1970s. For this paper, however, I could not obtain either a reliable estimate of cumulative exposure in the past or a personal exposure level of each worker during the study period. Therefore, according to the actual work done during the follow up period, subjects were divided into two groups. Those who had worked for more than one year in work areas where asbestos was processed, were considered to be exposed, and others were unexposed.

\section{FINDINGS OF PNEUMOCONIOSIS}

Chest radiography was carried out with standard procedures for Japan. ${ }^{9}$ Severity of pneumoconiosis in lung fields was classified into 12 grades from $0 /-$ to $3 /+$. According to the findings before the first survey and during the follow up period, subjects who continued to be classified as $0 /-, 0 / 0$, or $0 / 1$ were considered negative, and those who had been classified as $1 / 0,1 / 1$, or $1 / 2$ were considered positive. Those who had been classified as $2 / 1$, or more, were excluded from analysis. Furthermore, any subject who had moved from negative to positive or had shown a deterioration in the severity of pneumoconiosis during follow up, was also excluded from analysis. Pleural findings were not considered in this analysis.

\section{QUESTIONNAIRE SURVEY}

The standardised questionnaire of the American Thoracic Society (ATS-DLD-78A) ${ }^{10}$ was used with slight modification and translation into Japanese to assess smoking habit, as well as respiratory symptoms and medical histories. Mean cigarette consumption during the follow up period was calculated for each current smoker as the number of cigarettes smoked a day. For non-smokers, this was defined as zero.

\section{ANALYSIS}

All statistical tests and estimations were carried out with the SAS statistical packages at the Tokyo University Computer Center. Interaction of pneumoconiosis and exposure, and independent effects of each of these factors were estimated with an analysis of covariance (ANCOVA) in which the mean level of $\mathrm{FEV}_{1} / \mathrm{Ht}^{2}$ and smoking were treated as covariables.

\section{Results}

In 323 subjects out of the original 351 (92\%) forced spirometry was carried out acceptably three times or more and the effective duration of follow up was three years or more. Of these, we excluded 18 subjects who had changed their smoking habit during the follow up and nine whose chest $x$ ray film classification had been considered to be severe or who deteriorated during the study. There were 17 subjects with lowered routine spirometric results (the percentage predicted value of vital capacity calculated by the prediction equation used in Japanese pneumoconiosis law $^{9}$ ): VC $(\%)<80$ or the ratio of $\mathrm{FEV}_{1}(\%)$ to FVC $<70$ at their first examination. According to 
Table 1 Crude comparison of mean (SD) annual decline of FEV $V_{1}$ and FVC (adjusted for height squared $\left(H t^{2}\right)$ ) between those included in and excluded from analyses

\begin{tabular}{|c|c|c|c|}
\hline & $n$ & $\begin{array}{l}F E V / / H t^{2} \\
\left(m l / m^{2} / y\right)\end{array}$ & $\begin{array}{l}F V C / H t^{2} \\
\left(m l / m^{2} / y\right)\end{array}$ \\
\hline Those analysed & 242 & $-9 \cdot 1(11 \cdot 2)$ & $-5.5(13 \cdot 7)$ \\
\hline $\begin{array}{l}\text { Those excluded } \\
<30 \text { years old }\end{array}$ & $\begin{array}{l}81^{\star} \\
38\end{array}$ & $\overline{-}_{6} \cdot 0(10 \cdot 2)$ & $\overline{-}_{0.2(12.1)}$ \\
\hline $\begin{array}{l}\text { Change in smoking } \\
\text { habit }\end{array}$ & 18 & $-13 \cdot 5(10 \cdot 8)$ & $-7.4(15.4)$ \\
\hline $\begin{array}{l}\text { Low spirometry } \\
\text { Change in chest }\end{array}$ & $\begin{array}{r}17 \\
9\end{array}$ & $\begin{array}{l}-13 \cdot 8(15 \cdot 6) \\
-9 \cdot 6(12 \cdot 8)\end{array}$ & $\begin{array}{l}-10 \cdot 2(16 \cdot 7) \\
-5 \cdot 9(9 \cdot 7)\end{array}$ \\
\hline $\begin{array}{l}\text { Total acceptable } \\
\text { respondents }\end{array}$ & 323 & - & - \\
\hline
\end{tabular}

*One person had two reasons for being excluded.

the pneumoconiosis law in Japan, workers exposed to dust with reduced pulmonary function (as already described) are recommended to be transferred to work free from exposure to dust. Therefore the inclusion of subjects with reduced VC (\%) or $\mathrm{FEV}_{1}(\%)$ in the analysis may have caused a selection bias for the objectives of this study. Also, they could have shown variable aging patterns in pulmonary function due to this deterioration. For these reasons workers with low spirometric results were excluded from the analysis. I also excluded 38 subjects aged less than 30 at the first examination because their age related changes in $\mathrm{FEV}_{1}$ and FVC might have been different from those of the other middle aged subjects as a steady decline in $\mathrm{FEV} / \mathrm{Ht}^{2}$ seemed to occur after 30 years of age. Actually the mean (SD) $\mathrm{FEV}_{1} / \mathrm{Ht}^{2}$ was $-6.0(10.3)$ $\mathrm{ml} / \mathrm{m}^{2}$ in the $19-29$ year old group, and -9.8 $(9.8),-8.3(11.4)$, and $-10.0(12.5)$ in the 30-39 year old, 40-49 year old, and 50 year and over groups, respectively. So we analysed 242 middle aged subjects who had not shown changes in either their smoking habit or severity of pneumoconiosis during the follow up period, who had normal routine spirometric results at the first examination. Table 1 shows the mean (SD) of the slopes of $\mathrm{FEV}_{1} / \mathrm{Ht}^{2}$ and $\mathrm{FVC} / \mathrm{Ht}^{2}$, and compares those included in the analysis and those excluded.

Table 2 shows the means (SD) of some background variables by exposure to asbestos and pneumoconiosis grade. Subjects with fibrotic findings in the lungs were somewhat older than those without such findings. Although workers were recommended to stop

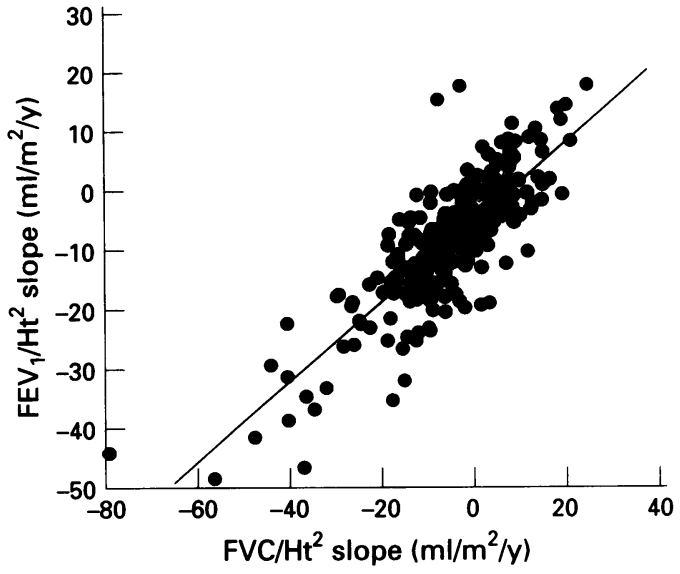

Figure 1 Two way scattergram of the slopes of $\mathrm{FEV} V_{1} / \mathrm{Ht}^{2}$ in all analysed subjects.

smoking, the habit was still very popular in the exposed group. Current cigarette consumption of smokers did not, however, differ significantly among the four categories. The values of routine spirometric indices, VC (\%) and $\mathrm{FEV}_{1}(\%)$, were fairly good at the first survey in all four categories, although a slight reduction of VC (\%) was noted in the workers with mild pneumoconiosis who were exposed to asbestos. There were some differences in $\mathrm{FEV} / \mathrm{Ht}^{2}$ among the four groups. The differences in chest radiographs were especially obvious and two way analysis of variance showed them to be significant $(P=0.001)$.

Figure 1 is a two way scattergram of the slopes of $\mathrm{FEV} / \mathrm{Ht}^{2}$ and $\mathrm{FVC} / \mathrm{Ht}^{2}$ among all analysed subjects. Although most of the slopes were between -20 and $+10 \mathrm{ml} / \mathrm{m}^{2} / \mathrm{y}$ in both indices, there seemed to be some rapid deteriorations, particularly in $\mathrm{FVC} / \mathrm{Ht}^{2}$.

Table 3 shows a simple comparison of the slopes expressed as mean (SEM) by exposure and severity of pneumoconiosis. The subjects with pneumoconiosis had a tendency to show faster annual declines in $\mathrm{FEV}_{1} / \mathrm{Ht}^{2}$ and $\mathrm{FVC} / \mathrm{Ht}^{2}$. The difference in slopes by exposure was less obvious. Most of the differences in the slopes of workers with and without pneumoconiosis seemed greater in the exposed group. This suggests a possible interaction of pneumoconiosis and exposure to asbestos on annual declines in $\mathrm{FEV}_{1} / \mathrm{Ht}^{2}$ and $\mathrm{FVC} / \mathrm{Ht}^{2}$.
Table 2 Mean (SD) of related variables

\begin{tabular}{|c|c|c|c|c|}
\hline & \multicolumn{4}{|l|}{ Pneumoconiosis } \\
\hline & \multicolumn{2}{|c|}{ Negative exposure to asbestos } & \multicolumn{2}{|c|}{ Positive exposure to asbestos } \\
\hline & $\stackrel{(-)}{(n=90)}$ & $\begin{array}{l}(+) \\
(n=109)\end{array}$ & $\stackrel{(-)}{(n=16)}$ & $\begin{array}{l}(+) \\
(n=27)\end{array}$ \\
\hline Age (y) & $43 \cdot 3(5 \cdot 4)$ & $43 \cdot 6(6 \cdot 2)$ & $46 \cdot 9(4 \cdot 9)$ & $48 \cdot 3(6 \cdot 5)$ \\
\hline $\begin{array}{l}\text { Smoking: } \\
\text { Smokers (\%) } \\
\text { Cigarettes/day (n) } \\
\mathrm{FEV}_{1} / \mathrm{Ht}^{2}\left(\mathrm{l} / \mathrm{m}^{2}\right) \\
\mathrm{VC}^{2}(\%)^{\star} \\
\mathrm{FEV}_{1}(\%)\end{array}$ & $\begin{array}{c}56.7 \\
20.0(7.5) \\
1.22(0.17) \\
104.0(11.8) \\
85.5(5 \cdot 6)\end{array}$ & $\begin{array}{c}69.4 \\
18.4(5.0) \\
1.20(0 \cdot 15) \\
102.6(10.4) \\
84.5(4.6)\end{array}$ & $\begin{array}{c}50 \cdot 0 \\
15 \cdot 9(5 \cdot 3) \\
1 \cdot 15(0 \cdot 18) \\
100 \cdot 1(14 \cdot 1) \\
86 \cdot 0(4 \cdot 2)\end{array}$ & $\begin{array}{l}73 \cdot 1 \\
17 \cdot 2(4 \cdot 0) \\
1 \cdot 07(0 \cdot 14) \\
94 \cdot 1(9 \cdot 5) \\
85 \cdot 3(4 \cdot 8)\end{array}$ \\
\hline
\end{tabular}

$\star \mathrm{VC}$ was based on the prediction equation used in the pneumoconiosis law of Japan. ${ }^{9}$
Table 3 Simple comparison of means (SD) of slopes of $\mathrm{FEV} / \mathrm{Ht} t^{2}$ and $\mathrm{FVCl} / \mathrm{Ht}^{2}\left(\mathrm{ml} / \mathrm{m}^{2} / \mathrm{y}\right)$ by exposure and penumoconiosis

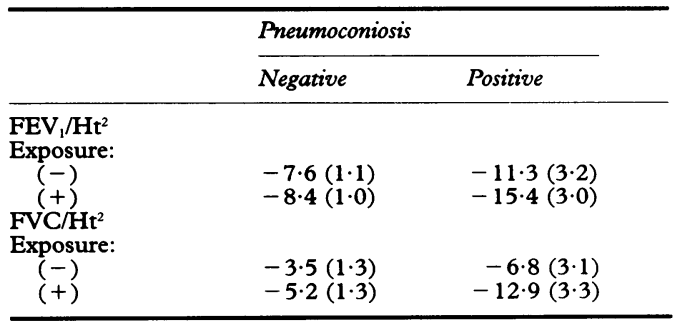


Table 4 Effects of age and smoking on mean (SD) annual declines in FEV, and FVC (adjusted for height squared $\left(H t^{2}\right)$ )

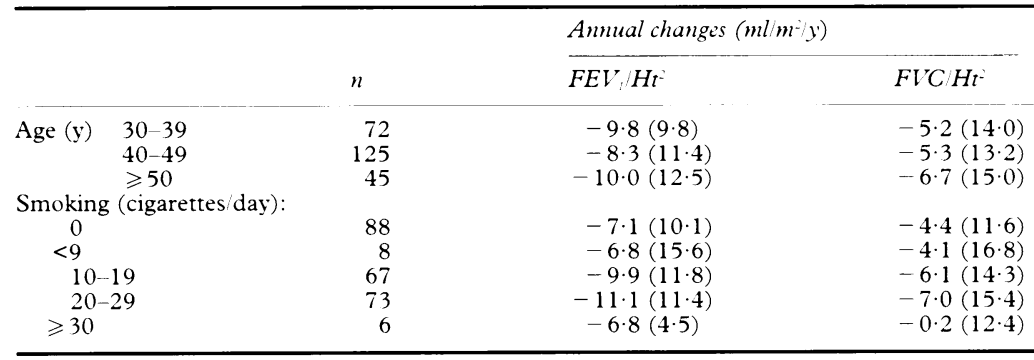

Figure 2 Relation between the mean $F E V_{i} / H t^{2}$ level and the slopes of $\mathrm{FEV}, / \mathrm{Ht}^{2}$ and $\mathrm{FVC} / \mathrm{Ht}^{2}$. First order regression lines are also shown.
Figure 3 Least square means of the slopes of $\mathrm{FEV} / \mathrm{Ht}^{2}$ and $\mathrm{FVC} / \mathrm{Ht}^{-}$ by pneumoconiosis and exposure, estimated by an analysis of covariance model including the interaction term of the two factors. The values have been adjusted for mean cigarette consumption and $\mathrm{FEV} / \mathrm{Ht}$ level. The significance of the interaction between pneumoconiosis and exposure to asbestos was $\mathrm{P}=0.45$ for $\mathrm{FVC} / \mathrm{Ht}^{2}$ and $P=0 \cdot 15$ for $F E V, / H t^{2}$
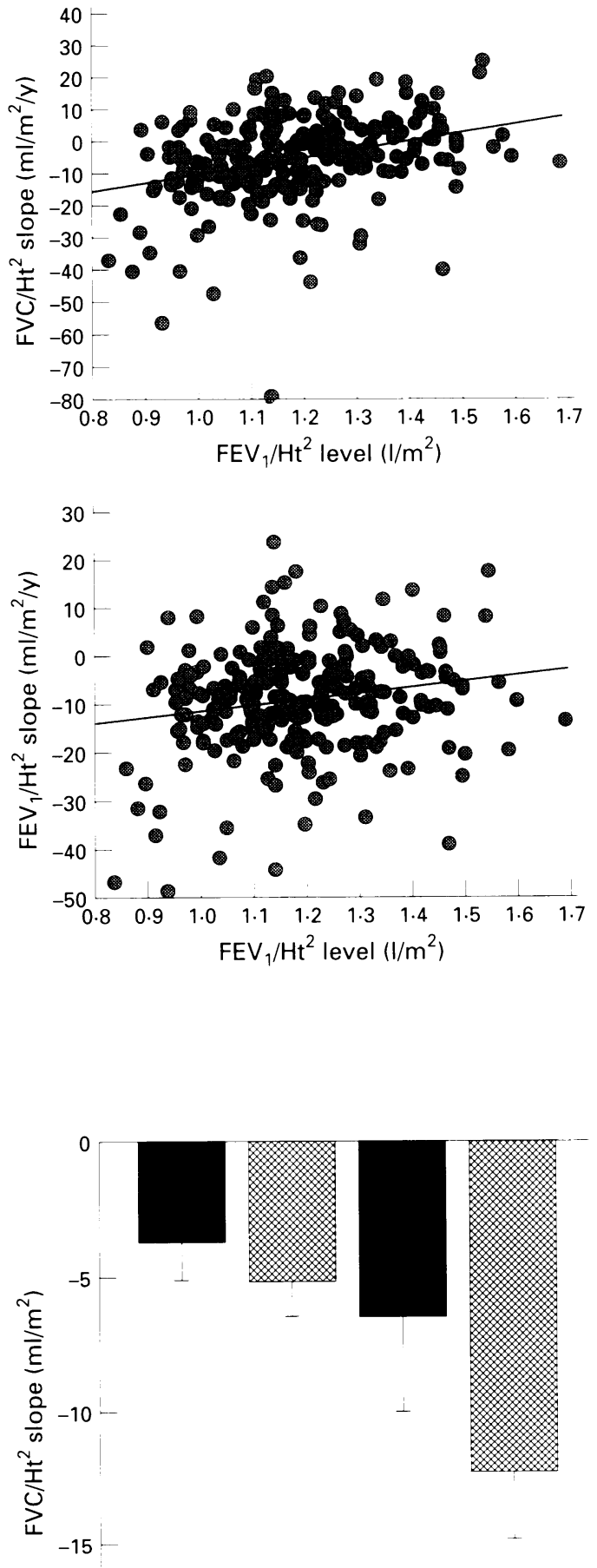

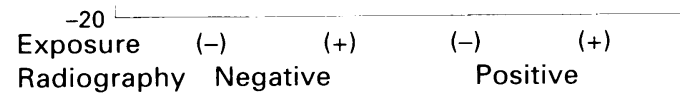

Table 4 shows the effects of age and current smoking on annual changes in $\mathrm{FEV}_{1} / \mathrm{Ht}^{2}$ and $\mathrm{FVC} / \mathrm{Ht}^{2}$. The effect of age was not clear, but the oldest group showed a slightly faster decline in both of the indices. A dose related acceleration due to smoking was found up to the category of 20 to 29 cigarettes a day.

The relation between the cross sectional level of $\mathrm{FEV}_{1}$ and the two longitudinal slopes were examined by regression analysis. Figure 2 shows a significant positive association with $\mathrm{FEV}_{1} / \mathrm{Ht}^{2}$ level in both change in $\mathrm{FEV}_{1} / \mathrm{Ht}^{2}(\mathrm{P}$ $<0.001)$ and change in $\mathrm{FVC} / \mathrm{Ht}^{2}(\mathrm{P}<0.001)$.

Analysis of covariance was conducted to avoid possible confounding, in which pneumoconiosis and exposure to asbestos were treated as independent factors (fig 3). At first, age, mean cigarette consumption, and $\mathrm{FEV}_{1} / \mathrm{Ht}^{2}$ level were considered as covariables. Age did not contribute greatly to the ANCOVA model (table 4). So age was then excluded from the analysis. Figure 3 shows the least square means (SEMs) of the slopes for pneumoconiosis and exposure to asbestos estimated with this model, adjusted for smoking and level of $\mathrm{FEV}_{1} / \mathrm{Ht}^{2}$. Although the least square mean in the exposed group suggested faster annual decline compared with the other three categories, particularly in $\mathrm{FVC} / \mathrm{Ht}^{2}$, there was no significant interactive contribution of the two factors either to the slope of $\mathrm{FEV}{ }_{1} / \mathrm{Ht}^{2}$ or to that of $\mathrm{FVC} / \mathrm{Ht}^{2}$.

Table 5 shows the independent effects of the factors and covariables estimated simultaneously by ANCOVA models, with the interaction between pneumoconiosis and exposure to asbestos being excluded, based on the results shown in fig 3 . Even after adjustment for smoking and $\mathrm{FEV}_{1} / \mathrm{Ht}^{2}$ level, pneumoconiosis contributed significantly to $\mathrm{FEV}_{1} / \mathrm{Ht}^{2}$ slope. The point estimate of the effect was $-4.9 \mathrm{ml} / \mathrm{m}^{2} / \mathrm{y}$ for the slope of $\mathrm{FEV}_{1} / \mathrm{Ht}^{2}$. This corresponds to an additional annual loss of 13 $\mathrm{ml}$ in $\mathrm{FEV}_{1}$ for a subject with an average height of $165 \mathrm{~cm}$. A similar tendency was found in the $\mathrm{FVC} / \mathrm{Ht}^{2}$ slope, but it was not significant. Mean cigarette consumption, as a
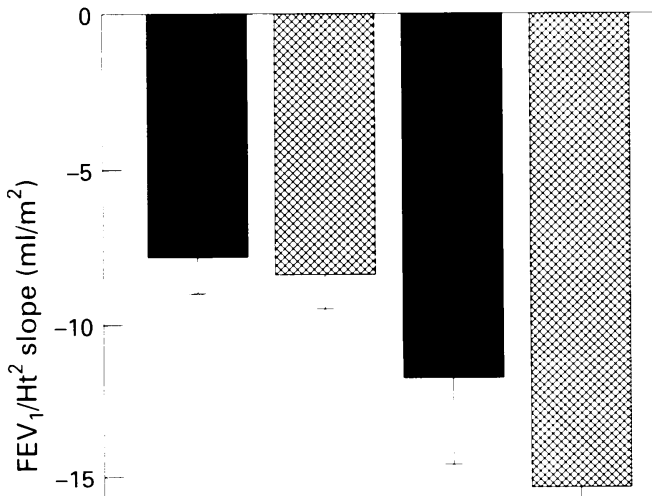

$\begin{array}{llll}\text { Exposure }(-) & (+) & (-) & (+) \\ \text { Radiography Negative } & \text { Positive }\end{array}$


Table 5 Independent effects of explanatory variables on annual change of $F E V_{1}$ and FVC (adjusted for height squared $\left(H t^{2}\right)$ ) estimated simultaneously by analysis of covariance

\begin{tabular}{|c|c|c|c|c|c|c|}
\hline & \multicolumn{6}{|c|}{ Annual changes $\left(\mathrm{ml} / \mathrm{m}^{2} / \mathrm{y}\right)$} \\
\hline & \multicolumn{3}{|c|}{$F E V, / H t^{2}$} & \multicolumn{3}{|c|}{$F V C / H t^{2}$} \\
\hline & Mean & (SEM) & Pvalue & Mean & (SEM) & Pvalue \\
\hline $\begin{array}{l}\text { Pneumoconiosis } \\
\text { Exposure } \\
\text { Smoking (pack/day) } \\
\mathrm{FEV}_{\mathrm{l}} / \mathrm{Ht}^{2}\left(1 / \mathrm{m}^{2}\right)\end{array}$ & $\begin{array}{r}-4.9 \\
-0.8 \\
-2.7 \\
9.5\end{array}$ & $\begin{array}{l}1 \cdot 9 \\
1 \cdot 4 \\
1 \cdot 4 \\
4 \cdot 5\end{array}$ & $\begin{array}{l}0.01 \\
0.58 \\
0.05 \\
0.03\end{array}$ & $\begin{array}{r}-3.7 \\
-1.6 \\
-1.0 \\
22.7\end{array}$ & $\begin{array}{l}2 \cdot 3 \\
1 \cdot 7 \\
1 \cdot 7 \\
5 \cdot 4\end{array}$ & $\begin{array}{r}0.10 \\
0.36 \\
0.54 \\
<0.01\end{array}$ \\
\hline
\end{tabular}

positive control in this analysis, was significantly associated with an accelerated decline of $\mathrm{FEV}_{1}$, but not with a decline in FVC. There was no significant contribution of exposure to asbestos on the slopes.

\section{Discussion}

The results of recent longitudinal studies in occupational cohorts exposed to mineral dusts and fibres have shown a significant association between such forms of exposure and accelerated annual loss of $\mathrm{FEV}_{1}{ }^{2-5}$ An important point in this context is that the association could be found even under relatively low exposure conditions. For example, in asbestos workers Ohlson and coworkers reported accelerated loss of FVC and $\mathrm{FEV}_{1}$ even in the workers who had retired from asbestos processing under exposures of around one or two fibres/ml. ${ }^{11}$ Another important point is the interaction of such low levels of exposure and pre-existing pulmonary fibrosis, because numerous workers who have mild pulmonary fibrosis due to a high level of exposure in the past are still working under the current conditions of low exposure. Therefore, it seems to be important to examine whether or not there is an interaction between current low exposure and pre-existing mild pulmonary fibrosis on deterioration of lung function, together with their independent effects.

In a simple comparison of the slopes of the categories defined by exposure and pneumoconiosis, in this study, the workers with fibrotic findings in the lungs, although their findings were mild and stable, had a tendency to show an accelerated slope compared with those who did not have fibrosis. Furthermore, it seemed that the tendency was more obvious in the exposed subjects. The ANCOVA analysis, however, indicated that the interaction of pneumoconiosis and exposure to asbestos did not contribute significantly to the slopes, when the two possible confounding factors, smoking and cross sectional level of $\mathrm{FEV}_{1}$, were taken into consideration. This result suggested that the effects of smoking and $\mathrm{FEV}_{1}$ level may have acted additively, although the possibility of type 2 error could not be neglected in assessing the interaction due to the few subjects in the exposed group.

The independent effect of pneumoconiosis on decline of $\mathrm{FEV} / \mathrm{Ht}^{2}$ was highly significant, even after adjustment for cigarette consumption and $\mathrm{FEV}_{1} / \mathrm{Ht}^{2}$ level. In other words, those workers with pre-existing mild fibrosis had accelerated annual loss in $\mathrm{FEV}_{1} / \mathrm{Ht}^{2}$. The independent effect of exposure to asbestos did not reach significance. As the difference in decline of $\mathrm{FEV}_{1}$ adjusted on cross sectional level indicates the potential causal role of a given factor on decline of $\mathrm{FEV}_{1}{ }^{12}$ pre-existing pulmonary fibrosis would be an independent risk factor for accelerated annual decline of $\mathrm{FEV}_{1}$ irrespective of exposure, even if it is mild and stable.

One possible source of bias in this analysis would be the selection bias, or the healthy worker effect. It is possible that those susceptible to exposure to asbestos and then inclined to rapid decline in $\mathrm{FEV}_{1}$ had been transferred from asbestos processing work to other safer or unexposed types of work before this study started. In that case, the exposed workers must have been healthier and less susceptible to exposure than the unexposed group. In other words, at the beginning of the study, the unexposed group might have included more of those with a natural rapid decline in FEV than the exposed group. If this is the case, it might partially explain why no difference in slopes by exposure to asbestos was detected in this study.

Table 2 shows that routine spirometric results of our subjects at the start of this study were good, and the unexposed subjects had rather better results than the exposed at the beginning of the study. Furthermore, our eligibility criteria for lung function would have excluded any subject who's lung function had deteriorated and may have led to work transfer. Also, any worker with fibrosis of grade $2 / 1$ and more was excluded from the analysis. Thus this study included only healthy subjects and subclinical cases and it is therefore unlikely that the healthy worker effect seriously biased our results.

Another important factor is past exposure. We can assume that cumulative exposure accelerates decline in both $\mathrm{FEV}_{1}$ and FVC independently from the current exposure. ${ }^{11}$ Because of this assumption, it is possible that the slope in old workers might be exaggerated. In my study, however, no notable age related difference in slopes was found. Therefore, it seems unlikely that the independent effect of pneumoconiosis has been seriously overestimated, although those workers with pneumoconiosis were slightly older than those without. It is still possible that the presence of fibrosis can simply be a marker of past heavy exposure, not necessarily a marker of susceptibility to accelerated decline in $\mathrm{FEV}_{1}$. Further analysis will be needed to make this point clear.

Among confounding factors, current cigarette consumption was negatively associated with $\mathrm{FEV}_{\mathbf{1}} / \mathrm{Ht}^{2}$ slope, but not with $\mathrm{FVC} / \mathrm{Ht}^{2}$ slope, in the ANCOVA analysis. Its contribution is a further $2.7 \mathrm{ml} / \mathrm{m}^{2}$ annual decline in $\mathrm{FEV}_{1} / \mathrm{Ht}^{2}$ for 20 cigarettes a day. This value is similar to the estimates reported previously. ${ }^{12} 13$ One interesting point is that pneumoconiosis contributed to the slopes of both $\mathrm{FEV}_{1} / \mathrm{Ht}^{2}$ and the $\mathrm{FVC} / \mathrm{Ht}^{2}$, but smoking contributed 
only to the $\mathrm{FEV}_{1} / \mathrm{Ht}^{2}$ slope. It is highly probable that the acceleration of annual decline in $\mathrm{FEV}_{1}$ by smoking reflects obstructive changes in the respiratory system. In the case of preexisting pulmonary fibrosis, however, the progression of restrictive disorders might be, at least in part, responsible for the acceleration, although its contribution to the $\mathrm{FEV}_{1} / \mathrm{Ht}^{2}$ slope was about twofold larger than that of smoking.

In conclusion, no definite evidence was obtained that supports the possibility of an interaction of pre-existing mild pulmonary fibrosis and low exposure to chrysotile asbestos on the accelerated annual decline of $\mathrm{FEV}_{1}$ and FVC. Even if it is mild and stable, however, pre-existing pulmonary fibrosis is an independent risk factor for accelerated annual decline of $F E V_{1}$ irrespective of exposure. As this study was based on only a few subjects, and past exposure before the start of the study was not considered, further investigation is needed to confirm the results.

This study was presented, in part, at the 24th International Conference on Occupational Health, Nice, 1993. Partly supported by Takeda Science Foundation, Japan.
1 Becklake MR. Occupational exposures: evidence for a causal association with chronic obstructive pulmonary causal association with chronic obstructive
disease. Am Rev Respir Dis 1989;140:S85-91.

2 Love RG, Miller BG. Longitudinal study of lung function in coalminers. Thorax 1982;37:193-7.

3 Attfield MD. Longitudinal decline in $\mathrm{FEV}_{1}$ in United States coalminers. Thorax 1985;40:132-7.

4 Hnizdo E. Loss of lung function associated with exposure to silica dust and with smoking and its relation to disability and mortality in South African gold miners. $B r f$ Ind Med 1992;49:472-9.

5 Siracusa A, Cicioni C, Volpi R, Canalicchi P, Brugnami G, Comodi AR, Abbritti G. Lung function among asbestos cement factory workers: cross-sectional and asbestos cement factory workers: cross-sectional

6 Nakadate T, Sato T, Kagawa J. Longitudinal changes in time domain spirogram indices and their variability. Eur time domain spirogram ind

7 Ferris BG. Epidemiology standardization project. Am Rev Respir Dis 1978;118:57-62.

8 Japan Association of Industrial Health. Recommendation on threshold limit values (1993). Fapanese fournal of Industrial Health 1993;35:323-45. (In Japanese.)

9 Department of Health and Safety. Ministry of Labor, Japan. Handbook for health examination on pneumoconiosis. Tokyo: Japan Safety and Health Association, 1978. (In Japanese.)

10 Ferris BG. Epidemiology standardization project. Am Rev Respir Dis 1978;118:10-35.

11 Ohlson CG, Bodin L, Rydman T, Högstedt C. Ventilatory decrements in former asbestos cement workers: a four year follow-up. Br F Ind Med 1985;42:612-6.

12 Fletcher C, Peto R, Tinker C, Speizer FE. The natural history of chronic bronchitis and emphysema. London: Oxford University Press, 1976.

$13 \mathrm{Xu} \mathrm{X}$, Dockery DW, Ware JH, Speizer EF, Ferris Jr BG. Effects of cigarette smoking on rate of loss of pulmonary function in adults: a longitudinal assessment. Am Rev Respir Dis 1992;146:1345-8.

\section{Vancouver style}

All manuscripts submitted to Occup Environ Med should conform to the uniform requirements for manuscripts submitted to biomedical journals (known as the Vancouver style.)

Occup Environ Med, together with many other international biomedical journals, has agreed to accept articles prepared in accordance with the Vancouver style. The style (described in full in the BMF, 24 February $1979, \mathrm{p}$ 532) is intended to standardise requirements for authors.

References should be numbered consecutively in the order in which they are first mentioned in the text by Arabic numerals above the line on each occasion the reference is cited (Manson ${ }^{1}$ confirmed other reports $^{2-5}$....). In future references to papers submitted to Occup Environ Med should include: the names of all authors if there are seven or less or, if there are more, the first six followed by et al; the title of journal articles or book chapters; the titles of journals abbreviated according to the style of Index Medicus; and the first and final page numbers of the article or chapter. Titles not in Index Medicus should be given in full.

Examples of common forms of references are:

1 International Steering Committee of Medical Editors, Uniform requirements for manuscripts submitted to biomedical journals. Br Med $\mathcal{f} 1979 ; 1: 532-5$.

2 Soter NA, Wasserman SI, Austen KF. Cold urticaria release into the circulation of histamine and eosinophil chemotactic factor of anaphylaxis during cold challenge. N Engl $\Im$ Med 1976;294:687-90.

3 Weinstein L, Swartz MN. Pathogenic properties of invading micro-organisms. In: Sodeman WA Jr, Sodeman WA, eds. Pathologic physiology, mechanisms of disease. Philadelphia: W B Saunders, 1974:457-72. 